\title{
Alt Yüzeyi Modifiye Edilmiş NACA 63-415 Kanat Profilinin Aerodinamik Performansının Sayısal Analizi
}

\author{
Hakan İnan ${ }^{1 *}$, Mahmut Kaplan ${ }^{2}$ \\ 1* Amasya Üniversitesi, Fen Bilimleri Enstitüsü, Makine Mühendisliği Bölümü, Amasya, Türkiye, (ORCID: 0000-0001-7654-9460), hakan.inan@,outlook.com \\ 2 Amasya Üniversitesi, Mühendislik Fakültesi, Makine Mühendisliği Bölümü, Amasya, Türkiye (ORCID: 0000-0003-2675-9229), mahmut.kaplan@amasya.edu.tr
}

(2nd International Conference on Applied Engineering and Natural Sciences ICAENS 2022, March 10-13, 2022)

(DOI: $10.31590 /$ ejosat.1077023)

ATIF/REFERENCE: İnan, H., Kaplan, M. (2022). Alt Yüzeyi Modifiye Edilmiş NACA 63-415 Kanat Profilinin Aerodinamik Performansının Sayısal Analizi. Avrupa Bilim ve Teknoloji Dergisi, (34), 121-125.

\section{$\ddot{O} \mathbf{z}$}

Nüfusun artması ve teknolojik gelişmelere bağlı olarak dünyada enerji tüketimi hızla artmaktadır. Fosil yakıtların rezervlerinin sınırlı olması ve çevreye olumsuz etkilerinden dolayı yenilenebilir enerji kaynakları önem kazanmıştır. Yenilenebilir enerji kaynaklarından biri olan rüzgârdaki kinetik enerjiyi elektrik enerjisine dönüştüren rüzgâr türbinlerinin veriminin artırılmasında kanat geometrisin tasarımı önemlidir. Bu çalışmada rüzgâr türbinlerinde kullanılan NACA 63-415 kanat profilinin alt yüzeyinin geometrisindeki değişikliğin aerodinamik performansa etkisi ANSYS Fluent hesaplamalı akışkanlar dinamiği (HAD) yazılımı ile sayısal olarak

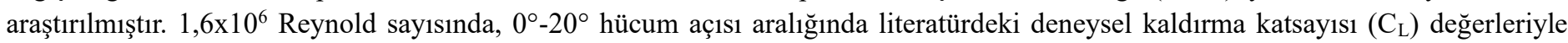
Spalarat Almaras ve SST k- $\omega$ türbülans modelleri kullanılarak elde edilen sayısal $C_{L}$ değerleri karşılaştırılmıştır. SST k- $\omega$ türbülans modeliyle elde edilen $\mathrm{Cl}$ değerleri deneysel verilere daha iyi uyum sağladığı için hesaplamalar bu modelle yapılmıştır. Bu çalışmada, NACA 63-415 kanat profilinin alt yüzeyinin boyutları $\% 10, \% 20$ ve $\% 30$ azaltılarak sirasiyla NCAY10, NCAY20 ve NCAY30 kanat profilleri üretilmiştir. Sayısal sonuçlar yeni kanat profillerinin NACA 63-415 kanat profiline göre aerodinamik performansı iyileştirdiğini ve maksimum $\mathrm{C}_{\mathrm{L}} / \mathrm{C}_{\mathrm{D}}$ değerlerinin $\mathrm{NCAY30}$ kanat profili ile elde edildiğini göstermiştir. Bu çalışmanın mevcut kanat profillerinin performansını artırmada literatüre katkıda bulunacağı düşünülmektedir.

\section{Numerical Analysis of the Aerodynamic Performance of the NACA 63-415 Airfoil with Modified Lower Surface}

\begin{abstract}
Energy consumption in the world is increasing rapidly due to population growth and technological developments. Renewable energy sources have gained importance thanks to fossil fuel reserves being limited and their negative impacts on the environment. The design of blade geometry is crucial to enhancing the efficiency of wind turbines that convert kinetic energy in the wind, one of the renewable energy sources, into electrical energy. In this study, the effect of the change in the geometry of the lower surface of the NACA 63-415 airfoil used in wind turbines on aerodynamic performance was investigated numerically with the ANSYS Fluent CFD software. The experimental lift coefficient $\left(\mathrm{C}_{\mathrm{L}}\right)$ values for a range of angles of attack $0^{\circ}$ to $20^{\circ}$ at a Reynolds number of $1.6 \times 10^{6}$ number, were compared with the numerical $C_{L}$ values obtained using Spalarat Almaras and SST k- $\omega$ turbulence models. Since $C_{L}$ values obtained by the SST $\mathrm{k}-\omega$ turbulence model fitted better with the experimental data, the calculations were performed using this model. In this study, NCAY10,
\end{abstract}

* Sorumlu Yazar: hakan.inan@outlook.com 
NCAY 20 and NCAY30 blade profiles were produced by reducing the dimensions of the lower surface of the NACA $63-415$ airfoil by $10 \%, 20 \%$ and $30 \%$, respectively. Numerical results showed that the new airfoils improved the aerodynamic performance compared to the NACA 63-415 airfoil and the maximum $C_{L} / C_{D}$ values were obtained using the NCAY30 airfoil. It is thought that this study will contribute to the literature on enhancing the performance of the existing airfoils.

Keywords: Wind Turbine, NACA 63-415 Airfoil, Airfoil Surface Shape, Aerodynamic Performance, CFD.

\section{Giriş}

Son yıllarda yüksek nüfus artışı, hızlı ekonomik büyüme, teknolojik gelişmeler ve bunlara bağlı olarak artan üretim ihtiyacı dünyada enerjiye olan talebin artmasına neden olmuştur. Kömür, petrol gibi fosil yakıtların rezervlerinin sınırlı olması ve bu yakıtların çevre üzerinde olumsuz etkileri nedeniyle rüzgâr, güneş ve biokütle gibi yenilenebilir kaynaklarla enerjinin karşılanması önem kazanmıştır. Rüzgâr enerjisi, sera gazı emisyonuna sebep olmayan ve atmosferde bol miktarda bulunan yenilenebilir enerji kaynağı olduğu için ayrı bir öneme sahiptir. Türkiye'de 2005 yılında Yenilenebilir Enerji Kaynakları Kanunu'nun çıkarılması ile rüzgar enerjisi ile ilgili çalışmalar artmıştır [1].

Rüzgâr türbinleri, rüzgârdaki kinetik enerjiden elektrik enerjisi üreten sistemlerdir. Son zamanlarda rüzgâr türbini üretim teknolojisindeki gelişmeler rüzgar enerjisiyle ilgili maliyeti düşürmüştür. Rüzgâr türbininin kanatlarının şekil ve boyutları, rüzgârdan enerjiyi verimli olarak almak için gereken aerodinamik performansa ve kanat üzerindeki kuvvetlere dayanması için gerekli mukavemete göre belirlenir. Kanat profilinin aerodinamik yapısı, tüm kanadın aerodinamik yapısını etkiler, dolayısı ile rüzgâr türbininin verimini iyileştirmede önemli bir etkendir [2]. Bir rüzgâr türbininde kanat performansı kanat yüzeyinde oluşan kaldırma ve sürükleme kuvveti ile doğrudan ilișkilidir. Kanat profilinin performansı kaldırma kuvveti katsayısı $\left(\mathrm{C}_{\mathrm{L}}\right)$, sürükleme kuvveti katsayısı $\left(\mathrm{C}_{\mathrm{D}}\right)$ ve kaldırma kuvvetinin sürüklenme kuvvetine oranı $\left(C_{L} / C_{D}\right)$ ile hesaplanmaktadır. $C_{L}$ ve $C_{D}$ aşağıda verilen denklemlerle ifade edilmektedir.

$$
C_{L}=\frac{F_{L}}{0,5 \rho V^{2} A}
$$

$$
C_{D}=\frac{F_{D}}{0,5 \rho V^{2} A}
$$

Burada, $F_{L}$ ve $F_{D}$ sirasıyla kanadın üzerine etki eden kaldırma ve sürükleme kuvvetleri, $\rho$ havanın yoğunluğu, $V$, serbest akış hızı, $A$ kanadın üst bakış alanı (kanat açıklığı ile veter uzunluğun çarpımı) ve $\rho$ havanın yoğunluğudur. $\mathrm{Bu}$ çalışmadaki tüm hesaplamalarda kanat açıklığ $1 \mathrm{~m}$ alınmıştır.

Ticari ölçekli rüzgâr türbinlerinde kanat profili olarak genellikle NACA serisi kanat profili kullanılmaktadır. Rüzgâr türbin kanat profillerinin aerodinamik performansı etkisini inceleyen birçok sayısal ve deneysel çalışma yapılmıştır.

Erişen ve Bakırcı [3], NACA 0012 ve NACA 4412 kanat profilleri kesit geometrisindeki değişiklikler yaparak elde edilen yeni kanat kesit geometrilerini $0^{\circ}, 4^{\circ}, 8^{\circ}, 12^{\circ}, 15^{\circ}, 16^{\circ}, 18^{\circ}$ hücum açılarında, $20 \mathrm{~m} / \mathrm{s}$ akış hızında, k- $\varepsilon$ türbülans modelini kullanarak hesaplamalı akışkanlar dinamiği (HAD) paket programı ile analiz etmiştir.
Sayısal sonuçlar genel olarak yeni kanat profillerinin NACA 0012 ve NACA 4412 kanat profillerine göre $C_{L}$ ve $C_{D}$ değerlerini artırdığını göstermiştir. Mevcut rüzgâr türbin kanatlarında performansı artırmak için $\mathrm{C}_{\mathrm{L}}$ değerini artıracak ve aynı zamanda $\mathrm{C}_{\mathrm{D}}$ değerini azaltacak yeni kanat profilleri geliştirilmelidir. Böylece aynı rüzgâr hızında daha yüksek tork elde edilerek türbin gücünde iyileşme sağlanacaktır.

Y1lmaz ve ark. [4], subsonik rüzgâr tünelinde 6,7 ve $8 \mathrm{~m} / \mathrm{s}$ rüzgar hızlarında $\left(12,6 \times 10^{4}, 14,7 \times 10^{4}, 16,8 \times 10^{4}\right.$ Reynold sayılarında) $-4^{\circ}-26^{\circ}$ hücum açılarında S826, NACA 4415 ve NACA 63-415 kanat profillerinin aerodinamik performanslarını incelemişler. Deneysel sonuçlar NACA 63-415 kanat profilinin diğer kanat profillerine göre tüm hızlarda $C_{D}$ değerleri daha düşük olduğu için $\mathrm{C}_{\mathrm{L}} / \mathrm{C}_{\mathrm{D}}$ değerlerinin daha yüksek olduğunu göstermiştir. $\mathrm{Bu}$ nedenle onlar NACA 63-415 kanat profilinin geniş hücum açısı aralığında, düşük hızda çalışan Rüzgar Enerji Santralleri için daha verimli olduğu sonucuna varmışlardır.

Şahin ve Acır [5], 10 m/s rüzgâr hızında (68490 Reynold sayısında), $0^{\circ}-20^{\circ}$ hücum açısı aralığında, NACA 0015 kanat profilinin aerodinamik performansinı deneysel ve sayısal olarak incelemiştir. Spalart Allmaras ve $\mathrm{k}-\varepsilon$ türbülans modelleri kullanılarak ANSYS Fluent yazılımıyla sayısal analiz yapılmıştır. Spalart Allmaras modeliyle elde edilen $C_{L}$ ve $C_{D}$ katsayılarının deneysel verilerle daha iyi uyum sağladığını gözlemlenmiştir. Ayrıca $16^{\circ}$ hücum açısından sonra $C_{L}$ katsayının azaldığını ve optimum kanat profil performansının $8^{\circ}$ hücum açısında gerçekleştiğini tespit etmişlerdir.

Soğukpınar [6], $50 \mathrm{~m} / \mathrm{s}$ rüzgâr hızında $\left(6 \times 10^{6}\right.$ Reynold sayısında), $0^{\circ}-14^{\circ}$ hücum açısı aralığında NACA 00XX (0008, 0009, 0010, 0012, 0015, 0018, 0021 ve 0024) kanat profillerinin SST (Shear Stress Transport) türbülans modelini kullanarak COMSOL yazılımıyla sayısal olarak analizini yapmıştır. HAD analizinin doğrulanması için NACA 0012 kanat profilinin $C_{L}$ ve basınç katsayısı $\left(\mathrm{C}_{\mathrm{P}}\right)$ ilgili deneysel verileri sayısal sonuçlarla karşılaştırmış ve birbirleriyle uyumlu olduğunu görmüştür. Bunun yanında kanat profillerinin kalınlığı $\operatorname{arttıkça~} C_{L}$ değerinin azaldığ 1 gözlemlemiştir.

Tanürün ve ark. [7], veter uzunluğun $8 \mathrm{~cm}$ olan NACA 0018 kanat profiline sahip $8 \mathrm{~cm}$ ve $16 \mathrm{~cm}$ kanat uzunluğunda iki kanat modelinin aerodinamik performansın $5,7 \times 10^{4}$ Reynold sayısında, $0^{\circ}-60^{\circ}$ hücum açısı aralığında deneysel ve sayısal olarak incelemişlerdir. Sayısal analiz, SST türbülans modeli kullanılarak ANSYS Fluent yazılımıyla yapmışlardır. Hem deneysel hem de sayısal çalışma sonucunda kanat uzunluğu $8 \mathrm{~cm}$ olan kanat modelinin kanat uzunluğu $16 \mathrm{~cm}$ olan kanat modeline göre aerodinamik veriminin $\left(\mathrm{C}_{\mathrm{L}} / \mathrm{C}_{\mathrm{D}}\right)$ daha iyi olduğu görülmüştür.

Düz [8], $0^{\circ}, 5^{\circ}, 10^{\circ}, 15^{\circ}, 20^{\circ}$ hücum açılarında ve $4,7,12,20$ m/s rüzgâr hızlarında FX84-W-218, SELİG S8036, FX 63-137 ve EPPLER 580 kanat profillerinin rüzgâr türbinlerinde verimine etkisini sayısal olarak incelemiştir. Sayısal sonuçlar tüm kanat profillerinin $C_{L} / C_{D}$ değerleri karşılaştırdığında bütün hücum açılarında FX 63-137 kanat profilinin en yüksek aerodinamik performansa sahip olduğu göstermiştir. Ayrıca incelenen tüm 
kanat profillerinde tüm hızlarda $3^{\circ}-7^{\circ}$ hücum açıSı aralığında maksimum performans elde edilmiştir.

Özkan ve Erkan [9], TSST (Transitional Shear Stress Transport) türbülans modeli kullanarak, $6^{\circ}$ hücum açısı için NACA 63-415 tipi rüzgar türbin kanadındaki pürüzlülügün (h, pürüzlülük yüksekliği $=0.1-0.5 \mathrm{~mm}$ ) aerodinamik performansa etkisini sayısal olarak incelemişlerdir. Onlar $10^{4}$ Reynold sayısına kadar NACA 63-415 kanat profilindeki pürüzlülüğün aerodinamik performansa etkisinin ihmal edilir seviyede olduğunu $5 \times 10^{4}-1.5 \times 10^{5}$ arasındaki Reynold sayılarında kanattaki pürüzlülüğün aerodinamik performansı artırdı̆̆ 1 tespit etmişlerdir. $2.5 \times 10^{5}$ Reynold sayısından sonra $C_{L} / C_{D}$ değeri düştüğü için kanattaki aerodinamik performansının azaldığını gözlemlemişlerdir.

Güleren ve Demir [10], $20 \mathrm{~m} / \mathrm{s}$ rüzgar hızında $\left(1,37 \times 10^{5}\right.$ Reynold sayısında), $0^{\circ}, 5^{\circ}, 10^{\circ}, 15^{\circ}$ ve $20^{\circ}$ hücum açılarında, Spalart-Allmaras türbülans modeli kullanılarak EPPLER 625, EPPLER 664, CLARK Y, EIFFEL 10 (Wright), FX 69-PR-281, NACA Munk M4 kanat profillerini sayısal analizini yapmışlardır. Sayısal sonuçlar diğer kanat profilleriyle kıyaslandığında $C_{L}$ ve $\mathrm{C}_{\mathrm{L}} / \mathrm{C}_{\mathrm{D}}$ açısından CLARK $\mathrm{Y}$ kanat profilinin en yüksek performansa sahip olduğu göstermiştir.

Bu çalışmada NACA 63-415 kanat profilinin alt yüzeyinin geometrisi değiştirilerek oluşturan kanat profillerinin aerodinamik performansa etkisi HAD yöntemiyle ANSYS Fluent programıyla sayısal analizi yapılmıştır. İlk önce sayısal sonuçlar NACA 63-415 kanat profilinin deneysel verilerle doğrulanmıştır. Daha sonra NACA 63-415 kanat profilinin alt yüzeyinin şekli değiştirilerek oluşturan profillerin aerodinamik performansa etkisi araştırılmıştır.

\section{Materyal ve Metot}

$\mathrm{Bu}$ çalışmada önce SOLIDWORKS programı kullanılarak NACA 63-415 kanat profilinin Şekil 1'de görüldüğü gibi iki boyutlu geometrisi elde edilmiştir. Kanat profilinin veter uzunluğu 1 m'dir.

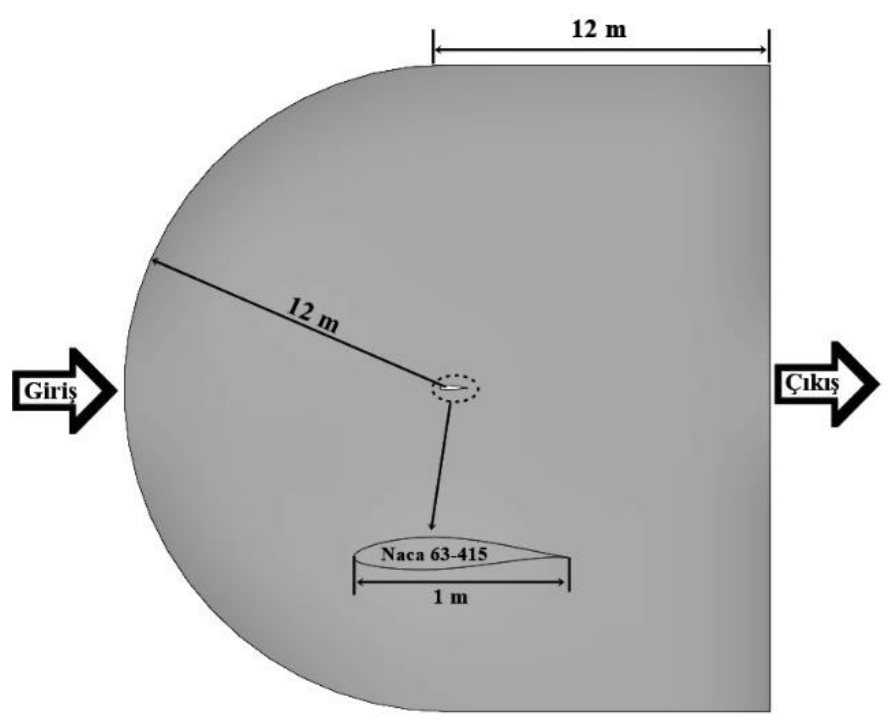

Şekil 1. Naca 63-415 kanat profili ve bölgesi

Daha sonra oluşturulan model ANSYS Workbench platformuna aktarılarak geometri bölümünde kanat profilinin e-ISSN: 2148-2683 etrafına akış bölgesi oluşturulmuştur. Şekil 1'de gösterildiği gibi akış alanını oluşturan yarım dairenin yarıçapı ve dikdörtgenin kenar uzunluğu, veter uzunluğunun 12 katı (12 m) olarak belirlenmiştir.

ANSYS Workbench platformunun Meshing (ağ oluşturma) bölümünde kanat modelinin ağı oluşturulmuştur ve sınır şartlarının adları girilmiştir. Şekil 2'de kanat profiline yakın bölgelerde yoğunlaştırılmış dörtgen elemanlardan oluşan sayısal ağ yapısı gösterilmiştir. Ağdan bağımsızlık testleri yapıldıktan sonra modelin ağ eleman sayısı 300250 olarak belirlenmiştir. Giriş sınır koşulu (inlet), çıkış sınır koşulu (outlet) ve kanat profili (airfoil) olarak isimlendirilmiştir.

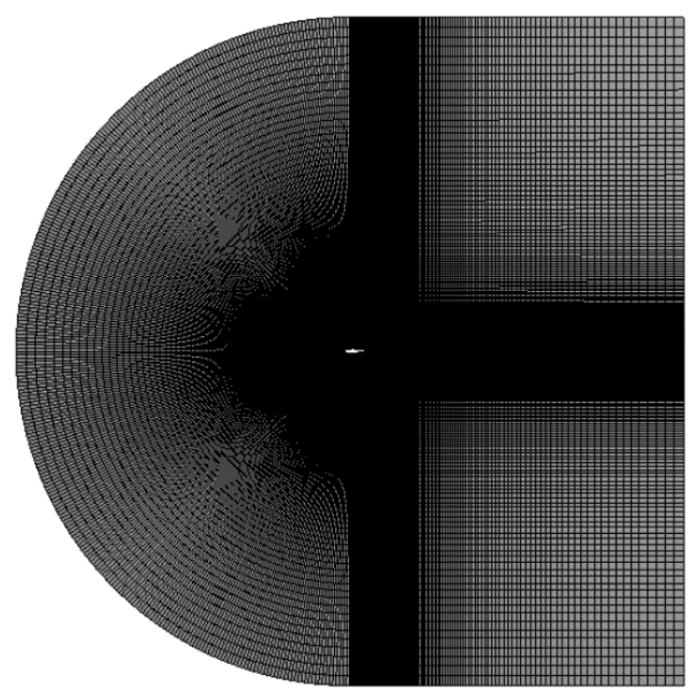

Şekil 2. Modelin ağ yapısı

Modelin ağ yapısı oluşturulduktan sonra ANSYS Workbench platformunun Setup kısmında havanın özellikleri, türbülans modeli ve sınır koşulları gibi gerekli bilgiler belirlenerek kanat profilinin sayısal analizi yapılmıştır. Kanat profili etrafındaki akış iki boyutlu, sıkıştırılamaz, sürekli ve türbülanslı olarak kabul edilmiştir. Havanın yoğunluğu $1,225 \mathrm{~kg} / \mathrm{m}^{3}$, dinamik viskozitesi $1,7894 \times 10^{-5} \mathrm{~kg} / \mathrm{m} . \mathrm{s}$ olarak alınmıştır. Hesaplamalarda yakınsama kriteri tüm büyüklükler için $10^{-6}$ alınmıştır.

\subsection{Türbülans Modeli}

$\mathrm{Bu}$ çalışmada Spalarat Almaras ve SST k- $\omega$ türbülans modelleri kullanılmıştır. Spalart - Allmaras türbülans modeli düşük Reynolds sayılı akışlarla ilgili aerodinamik problemler için geliştirilmiştir [11]. Bu modelde türbülans viskoziteyi çözmek için bir adet taşınım denklemi vardır. SST (Shear-Stress Transport) k- $\omega$ türbülans modeli $\mathrm{k}-\varepsilon$ ve $\mathrm{k}-\omega$ modellerinin birleştirilmesi oluşmuştur [12]. SST k- $\omega$ türbülans modeli $\mathrm{k}$ (türbülans kinetik enerji) ve özgül yutulma $(\omega)$ için iki adet taşınım denklemi vardır. SST k- $\omega$ türbülans modeli sınır tabaka içerisinde standard k- $\omega$ türbülans modeli gibi, duvardan uzak bölgelerde ise $\mathrm{k}-\varepsilon$ türbülans modeli gibi davranmaktadır [13].

\subsection{Sınır Koşulları}

Havanın giriş kısmına hız girişi koşulu uygulanmıştır. Tüm hesaplamalarda hava giriş hızı $1,6 \times 10^{6}$ Reynold sayısında belirlenmiştir. Havanın çıkış kısmına basınç çıkışı sınır koşulu uygulanmıştır. Çıkış sınır koşulunda havanın basıncı 1 atm olarak 
belirlenmiştir. Kanat profili sınırlarına duvar sınır koşulu uygulanmıştır ve duvar pürüzsüz olarak belirlenmiştir.

\section{Araştırma Sonuçları ve Tartışma}

\subsection{Sayısal Sonuçların Doğrulanması}

$\mathrm{Bu}$ çalışmada rüzgar türbini kanat profili kataloğunda [14]

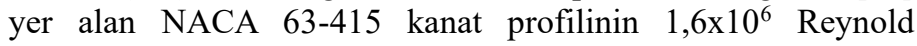
sayısında, $0^{\circ}-20^{\circ}$ hücum açısı aralığında deneysel verileri kullanılarak Spalarat Almaras ve SST k- $\omega$ türbülans modelleriyle yapılan hesaplamaların doğrulaması yapılmıştır. Şekil 3'te görüldüğü gibi Spalarat Almaras modeliyle kıyaslandığında SST $\mathrm{k}-\omega$ türbülans modeliyle hesaplanan $\mathrm{C}_{\mathrm{L}}$ değerleri deneysel $\mathrm{C}_{\mathrm{L}}$ değerlerine daha uyumludur. Maksimum $C_{L}$ değeri deneysel ve sayısal olarak sırasıyla $13,4^{\circ}$ ve $14^{\circ}$ hücum açısında elde edilmiştir.

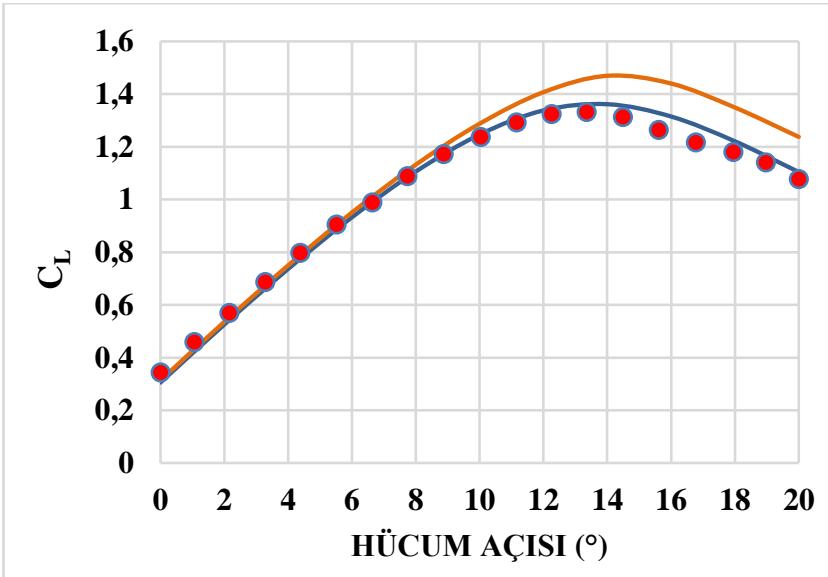

- Deney $[14] \longrightarrow$ SST k- - Spalart-Allmaras

Şekil 3. Sayısal ve Deneysel $C_{L}$ değerlerinin karşılaştırılması

\subsection{Kanat Yüzey Geometrisindeki Değişikliğin Performansına Etkisi}

Şekil 4'te NACA 63-415 kanat profilinin alt yüzeyinin geometrisi $\% 10, \% 20$ ve \% 30 değiştirilerek üretilen kanat profilleri görülmektedir. Şekil 4'te görüldüğü gibi yeni oluşturulan kanat profilleri alt yüzeyin küçültülmesine uygun olarak NCAY10 (\% 10), NCAY20 (\% 20) ve NCAY30 (\% 30) olarak adlandırılmıştır.

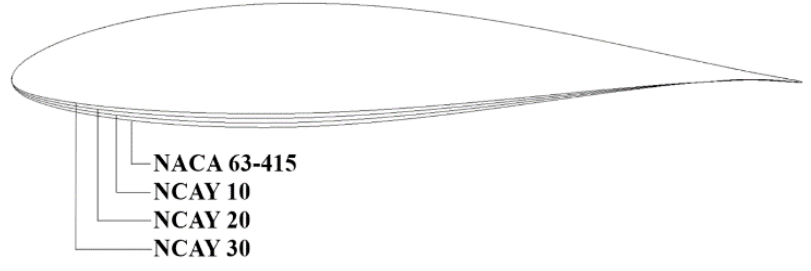

Şekil 4. Oluşturulan kanat profilleri

Şekil 5, Şekil 6 ve Şekil 7'de 1,6×106 Reynold sayısında, $0^{\circ}$ $20^{\circ}$ hücum açısı aralığında, yeni oluşturulan kanat profillerinin $\mathrm{C}_{\mathrm{L}}, \mathrm{C}_{\mathrm{D}}$ ve $\mathrm{C}_{\mathrm{L}} / \mathrm{C}_{\mathrm{D}}$ için NACA 63-415 kanat profiliyle karşılaştırılması görülmektedir.
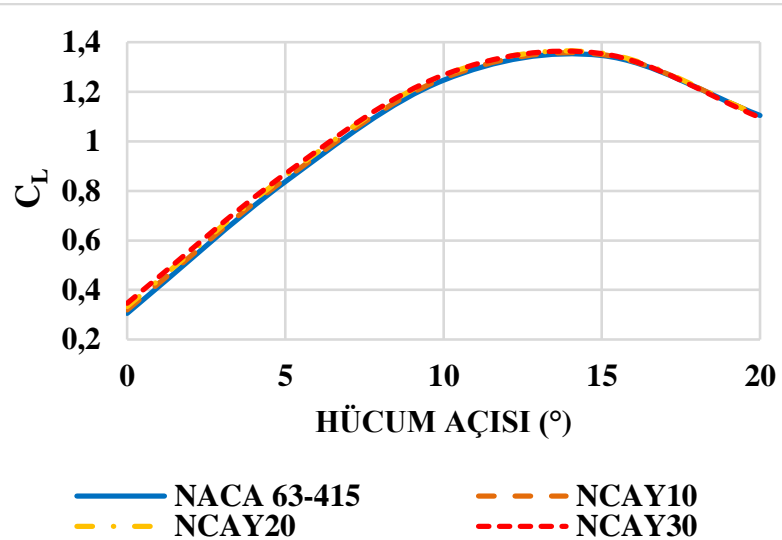

Şekil 5. Alt yüzey geometrisinin $C_{L}$ 'ye etkisi
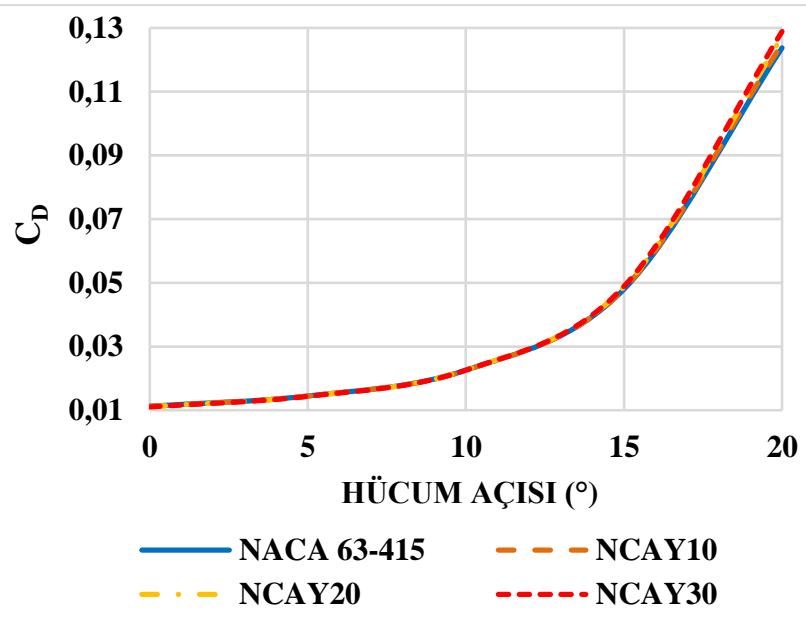

Şekil 6. Alt yüzey geometrisinin $C_{D}$ ’ye etkisi

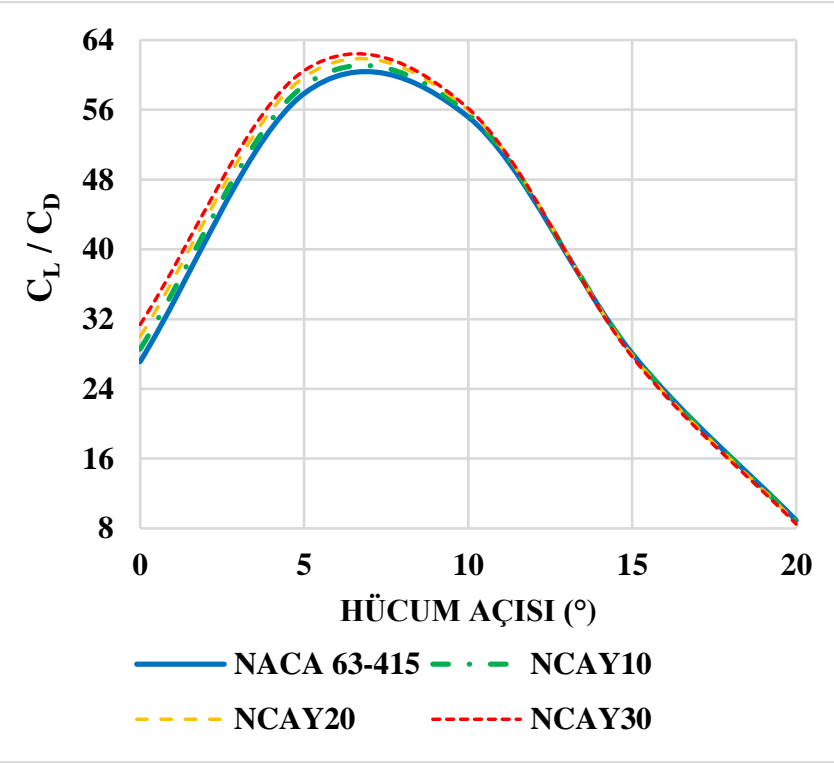

Şekil 7. Alt yüzey geometrisinin $\mathrm{C}_{\mathrm{L}} / \mathrm{C}_{\mathrm{D}}$ 'ye etkisi

Şekil 5 ve Şekil 6'da görüldüğü gibi yeni oluşturulan kanat profilleri NACA 63-415 kanat profili ile kıyaslandığında $15^{\circ}$ hücum açısına kadar $C_{L}$ değerini artırırken, $C_{D}$ değerinde ise belirgin bir değişikliğe neden olmamıştır. $15^{\circ}$ hücum açısından sonra ise üretilen kanat profilleri $C_{D}$ değerinde artırırken $C_{L}$ değerini değiştirmede hemen hemen bir etkisi olmamıştır. Bunlara paralel olarak Şekil 7'de görüldüğü gibi yeni kanat profilleri 
yaklaşık $12^{\circ}$ hücum açısına kadar $\mathrm{C}_{\mathrm{L}} / \mathrm{C}_{\mathrm{D}}$ değerlerini artırmıştır ve diğer hücum açılarında da $\mathrm{C}_{\mathrm{L}} / \mathrm{C}_{\mathrm{D}}$ değerlerini azaltıcı bir etkisi yoktur. Maksimum $\mathrm{C}_{\mathrm{L}} / \mathrm{C}_{\mathrm{D}} \mathrm{NCAY30}$ kanat profilinde elde edilmiştir.

\section{Sonuç}

Bu çalışmada $1,6 \times 10^{6}$ Reynold sayısında, $0^{\circ}-20^{\circ}$ hücum açısı aralığında NACA 63-415 kanat profilinin alt yüzeyinin şekli değiştirilerek oluşturan kanat profillerinin aerodinamik performansa etkisi hesaplamalı akışkanlar dinamiği (HAD) yöntemiyle ANSYS Workbench paket programıla sayısal analizi yapılmıştır.

Literatürdeki [14] deneysel $C_{L}$ değerleri Spalart Allmaras ve SST k- $\omega$ türbülans modelleriyle elde edilen $\mathrm{C}_{\mathrm{L}}$ değerleriyle karşılaştırılmış ve SST k- $\omega$ türbülans modelinin deneysel verilere daha uyumlu olduğu görülmüştür. Sayısal verilerin deneysel verilerden farklı olmasının önemli sebeplerden biri sayısal çalışmada kanat yüzeyinin pürüzsüz kabul edilmesidir.

$\mathrm{C}_{\mathrm{L}} / \mathrm{C}_{\mathrm{D}}$ rüzgâr türbinin aerodinamik performansını belirleyen en önemli parametrelerinden biridir ve mevcut çalışmalarda önerilen kanat profillerinin sadece $\mathrm{C}_{\mathrm{L}}$ 'yi artırması aerodinamik performansı iyileştirmede yeterli olmadığını göstermiştir. $\mathrm{C}_{\mathrm{L}} / \mathrm{C}_{\mathrm{D}}$ 'nin artması için $\mathrm{C}_{\mathrm{L}}$ artarken $\mathrm{C}_{\mathrm{D}}$ 'nin azalması veya sabit kalması gerekmektedir. Üretilen kanat profilleri $C_{L}$ artarken $\mathrm{C}_{\mathrm{D}}$ 'de önemli bir artma olmadığı için $\mathrm{C}_{\mathrm{L}} / \mathrm{C}_{\mathrm{D}}$ değerini $12^{\circ}$ hücum açısına kadar artırmış ve bundan sonra $C_{L} / C_{D}$ değerini azaltıcı bir etkisi olmamıştır. Maksimum $C_{L} / C_{D}$ değerleri NCAY30 kanat profili ile elde edilmiştir.

\section{Kaynakça}

[1] AYDIN, İ. (2013). Balikesir'de Rüzgâr Enerjisi. Doğu Coğrafya Dergisi, 18(29), 29-50.

[2] Martin O.L. Hansen, Aerodynamics of Wind Turbine, Second Edition, Earthscan, UK and USA, 2008.

[3] Erişen, A., \& Bakırc1, M. (2014) "NACA 0012 ve NACA 4412 kanat kesitlerinin yeniden tasarlanarak HAD ile analiz edilmesi," Mühendislik ve Teknoloji Bilimleri Dergisi, 1: 5082.

[4] Yılmaz, İ., Çam, Ö., Taştan, M., \& Karc1, A. (2016) "Farklı Rüzgar Türbin Kanat Profillerinin Aerodinamik Performansının Deneysel İncelenmesi," Politeknik Dergisi, 19(4), 577-584.

[5] Şahin, İ. \& Acır, A. (2015) "Numerical and experimental investigations of lift and drag performances of NACA 0015 wind turbine airfoil," International Journal of Materials, Mechanics and Manufacturing, 3(1): 22-25

[6] Sogukpinar, H. (2017) "Numerical simulation of 4-digit inclined NACA 00xx airfoils to find optimum angle of attack

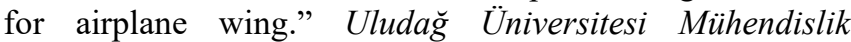
Fakültesi Dergisi, 22(1), 169-178.

[7] Tanürün, H. E., Ata, İ., Canlı, M. E., \& Acır, A. (2020) "Farklı açıklık oranlarındaki NACA-0018 rüzgâr türbini kanat modeli performansının sayısal ve deneysel incelenmesi," Politeknik Dergisi, 23(2): 371-381.

[8] Düz, H. (2016) "Rüzgar türbinleri için farklı kanat profillerinin sayısal olarak test edilmesi," Academic Platform Journal of Engineering and Science, 4(2).
[9] Özkan, M., \& Erkan, O. (2022) “Control of a boundary layer over a wind turbine blade using distributed passive roughness," Renewable Energy, volume 184, pages 421-429.

[10] Güleren, K. M., \& Demir, S. (2011) "Rüzgar türbinleri için düşük hücum açılarında farklı kanat profillerinin performans analizi," Isı Bilimi ve Tekniği Dergisi, 31(2), 51-59.

[11] Spalart; P., Allmaras; S., (January 1992) "A one-equation turbulence model for aerodynamic flows," 30th Aerosp. Sci. Meet. Exhib.

[12] ANSYS FLUENT 19.2 (2018) Theory Guide, Ansys Inc., Canonsburg PA, USA.

[13] Langtry, R. B. \& Menter, F. R. (2009) “Correlation-based transition modeling for unstructured parallelized computational fluid dynamics codes," AIAA Journal, 47(12), 2894-2906.

[14] Bertagnolio, F., Sørensen, N., Johansen, J., \& Fuglsang, P. (2001) "Wind turbine airfoil catalogue," Denmark. Forskningscenter Risoe. Risoe-R No. 1280(EN). 